\title{
Persistent social class mortality differences in New Zealand men aged 15-64: an analysis of mortality during 1995-97
}

\author{
Neil Pearce \\ Department of Medicine, Wellington School of Medicine, and Centre for Public \\ Health Research, Massey University Wellington Campus, New Zealand

\section{Peter Davis and Andrew Sporle \\ Department of Public Health, Christchurch School of Medicine, New Zealand}

t t has long been established that socioeconomic factors are major determinants of health and mortality. ${ }^{1}$ However, although the existence of such inequalities is well established, it has not been established as to which socio-economic factors are most important or whether there is a generic package of socio-economic disadvantage that drives the social patterning of health. Socio-economic factors such as income, education, area characteristics and occupation are all strongly related to overall health, ${ }^{1}$ although the patterns are different for different diseases. ${ }^{2}$ These various socioeconomic factors are all correlated with each other and few studies have had the necessary data, or the necessary statistical power and measurement accuracy, to attempt to separate their effects. Thus, the choice of measure has largely depended on practical considerations, such as the availability of occupational information on death certificates $^{1}$ or the availability of mortality data by areas grouped according to an index of deprivation. ${ }^{3}$

Thus, 'social class' can be used as a convenient summary term for various socioeconomic factors such as education, income, assets, housing and occupation, but can also be used to denote more profound divisions within society. Whatever its interpretation, it is of interest to assess the strength of social class differences in mortality in New Zealand and the extent to which these are increasing or decreasing over time. Social class mortality differences in New Zealand males aged 15-64 have previously been investigated for the period $1975-77^{1,2,4-6}$ and $1985-87^{7}$ using the Elley-Irving scale, which groups occupations into six socio-economic categories. ${ }^{8-11}$ This analysis has now been repeated for the period 1995-97 using the recently developed New Zealand Socioeconomic Index (NZSEI). ${ }^{12}$ In this paper, we describe the trends and patterns in overall male mortality. The social class mortality patterns in the Maori and non-Maori populations are described separately in an accompanying paper. ${ }^{13}$

\section{Methods \\ Mortality and Census data}

The study involved an analysis of deaths in all New Zealand men aged 15-64 during 1995-97, together with further analyses of the mortality data for 1985-87 and 1975-77. The methodology for the analyses of the data from the former two time periods has been described previously, ${ }^{1,7}$ and involved grouping the numerator (death) data and denominator (Census) data into social classes using three-digit codes of the 1968 version of the New Zealand Standard Classification of Occupations (NZSCO-68). ${ }^{14}$ For the 199597 analyses, the denominator data for all men aged 15-64 was supplied by Statistics New Zealand using data from the 1996 New Zealand Census; the analysis was restricted

\section{Abstract}

Objective: Social class mortality differences in New Zealand men aged 15-64 years have previously been examined for the periods $1975-77$ and 1985-87 using the Elley-Irving social class scale. The objective was to repeat these analyses for 1995-97 in order to examine time trends, and to assess current social class patterns of mortality.

Methods: Age-standardised mortality rates were calculated for each social class and a weighted estimate of the social class mortality gradient was obtained.

Results: Male mortality declined $21 \%$ between 1985-87 and 1995-97, but the social class mortality differences have not diminished and may have even increased. The Relative Index of Inequality has increased from 1.8 in 1975-77 to 2.1 in $1985-87$ and 2.3 in 1995-97. Unlike previous analyses, the relative social class mortality gradient was just as strong in the older age groups as in the younger age groups, indicating that the possible increase in social class gradient has largely occurred in the older age groups.

Conclusions: These findings indicate that the potential to address the excess preventable mortality caused by socioeconomic factors has not been fully realised in New Zealand.

Implications: Social class analyses identify groups in the community that have an excess mortality that is potentially preventable. There are still major social class differences in mortality in New Zealand, and these differences may even have increased. It is important that these patterns are taken into account in public health planning and that further research is conducted to identify the mechanisms by which these differences occur.

(Aust N Z J Public Health 2002; 26: 17-22)
Correspondence to:

Neil Pearce, Centre for Public Health Research, Massey University Wellington Campus, Private Box 756, Wellington New Zealand. Fax: +64 4380 0600; e-mail: n.e.pearce@massey.ac.nz
Submitted: March 2001

Revision requested: November 2001 Accepted: December 2001 
to this age range because of the need for occupational information. The numerator data involved deaths in men aged 15-64 years during 1995-97 and were supplied by the New Zealand Health Information Service.

\section{Classification of occupation}

The classification of the mortality data was based on the 'current or most recent occupation' coded to the three-digit level of the 1990 version of the New Zealand Standard Classification of Occupations (NZSCO-90) ${ }^{15}$ and the Census occupational information (on 'current occupation') was also obtained in three-digit occupational groups. As in previous analyses, ${ }^{1,7}$ occupational information from death certificates was found to be inadequate for social class categorisation in women. Thus, the study was once again confined to men aged 15-64.

\section{Classification of social class}

The previous analyses ${ }^{7}$ were based on the Elley-Irving socioeconomic scale. Occupations are classified into a six-point scale using an equal weighting of median income and median education level (class 1 is the 'highest' and class 6 is the 'lowest' socioeconomic group). In each instance, individuals were allocated to a particular social class on the basis of the 1968 version New Zealand Standard Classification of Occupations (NZSCO). ${ }^{14}$ However, the 1996 Census data and the 1995-97 mortality data use the 1990 version of the NZSCO. ${ }^{15}$ This represented a major change in the NZSCO codes from a status-based to a skills-based system, and there is no straightforward mapping between the two sets of codes. Thus, it was not possible to analyse the 1995-97 mortality rates using the Elley-Irving classification and the accompanying coding system that had been used previously.

The data were therefore instead analysed using the recently developed New Zealand Socio-Economic Index. ${ }^{12}$ This was developed using the three-digit NZSCO-90 codes with each occupational category being allocated a score between one and 100 based on a 'returns to human capital' model of the social stratification process. The index was developed based on the $1991 \mathrm{New}$ Zealand Census and the construct validation was carried out on data from the 1992/93 nationwide Household Health Survey using three indicators (self-assessed health, cigarette smoking and general practitioner visits). ${ }^{12}$ The findings were consistent with the expected socio-economic patterns and it was concluded that the NZSEI "has a clear conceptual basis, updates existing SES scales, and provides a link to international standards in SES and occupational classification".

For the purposes of the current analyses, the NZSEI scores for the various occupations were grouped into the standard six categories: <30, 30-39, 40-49, 50-59, 60-74, and 75+. ${ }^{12}$ There is some debate about the validity of the cutoff point for the highest social class category, and there would be some justification for using a cutoff of 70 rather than 75 (Blakely, personal communication). However, we used a cutoff of 75 for reasons of consistency with the published scale, ${ }^{12}$ and in any case our focus was on the overall social class mortality trend rather than in the findings for specific social class categories. Thus, both the denominator (1996 Census) and numerator (deaths during 1995-97) data were grouped into the standard six NZSEI categories using the threedigit NZSCO codes. Previous analyses ${ }^{11}$ had shown that farmers and agricultural workers represented a unique socio-economic grouping for which there is insufficient information (in the NZSCO-90 codes) for valid social class classification. Therefore, farmers and agricultural workers were excluded from the analyses (these represented $8.4 \%$ of the deaths and $7.5 \%$ of the Census data).

\section{Data analysis}

In each set of analyses, directly age-standardised mortality rates per 100,000 person-years were calculated for each social class. ${ }^{16}$ All data were classified into five-year age groups and Segi's world population ${ }^{17}$ was used as the standard. The class-specific findings were also presented as standardised rate ratios (SRRs); these represent the relative risk of mortality in each class compared with that for classes 1-6 combined.

The strengths of the social class mortality trends were assessed using a weighted linear regression of the age-standardised (or agespecific) class-specific mortality rates in order to estimate the slope of the overall age-standardised social class mortality trends. ${ }^{18,19}$ These mortality rates were regressed against the social class scores (in percentiles) for the midpoint of each social class category, with the regression weighted by the inverse variance of the rate for each class. The resulting regression coefficient and intercept were then used to estimate the Relative Index of Inequality, ${ }^{19}$ which is the predicted relative risk for the 100th percentile (intercept + $100 *$ slope) against the 0 th percentile (intercept only).

\section{Results}

In men aged 15-64 years, there were 14,572 deaths during 197577 , of which it was possible to classify $92 \%(13,423)$ into social classes (based on occupation). During 1985-87 there were 13,555 deaths, of which it was possible to classify $81 \%(11,013)$ into social classes. During 1995-97, there were 11,658 deaths of which it was possible to classify $78 \%(9,104)$ into social classes. Similarly, it was possible to classify $86 \%$ of the 1976 Census data, $81 \%$ of the 1986 Census data and $69 \%$ of the 1996 Census data into social classes. Thus, the unclassifiable category (which includes students, retired persons, invalids and the unemployed) increased from $8 \%$ to $19 \%$ to $22 \%$ of deaths, and from $14 \%$ to $19 \%$ to $31 \%$ of the denominator data from the Census. The latter increase is presumably due in part to the striking increase in unemployment over this period. ${ }^{20}$ However, it is not known whether this fully accounts for the increase in the proportions of deaths that were unclassifiable.

Table 1 shows the Elley-Irving social class distribution for New Zealand males aged 15-64 in 1976 and 1986. There was a small increase in the proportion of men in Elley-Irving classes 1 and 2 (high socio-economic status) and a small decrease in the proportion in classes 5 and 6 (low socio-economic status) in this time period. Table 1 also shows the 1996 NZSEI social class 
distribution, which is generally similar to that for the Elley-Irving scale, except that the NZSEI scale has a lower proportion of people in the highest social class category (4.9\% compared with 5.7\% and $6.4 \%)$ and a higher proportion in class 2 (18.0\% compared with $12.1 \%$ and $9.7 \%$ ).

The overall age-standardised mortality rate for men aged 1564 was 338 per 100,000 person-years during 1995-97, a decrease of $21 \%$ compared with $1985-87$. It is difficult to make valid comparisons of the pooled rates for classes 1-6 (i.e. excluding the unclassifiable category) with the overall mortality rate (i.e. including the unclassifiable category), because of the intractable problems with occupational classification. In particular, a relatively high proportion of deaths were classifiable because the death certificate records the current or most recent occupation, whereas the Census only records the current occupation. Consequently, in all three time periods the pooled rate for classes 1-6 was higher than the overall mortality rate (see Table 2). For this reason, all social class analyses were restricted to comparing the death rate in each class with the pooled rate for classes 1-6, and the data for the unclassifiable category was excluded from all further analyses.

Table 2 shows the age-standardised mortality rates and standardised rate ratios in the three time periods under study. In 197577 , the mortality rate varied from 451 per 100,000 person-years in Elley-Irving class 1 to 864 per 100,000 person-years in class 6 . When the mortality rates were divided by the pooled rate for classes 1-6 (568 per 100,000 person-years), this yielded overall SRRs of 0.79 for class 1 and 1.52 for class 6 . The overall social class mortality slope (the increase in the mortality rate per percentile change in social class score) was 3.37 per 100,000 person-years and the Relative Index of Inequality was 1.8 , i.e. the
Table 1: Social class distribution of employed New Zealand males aged 15-64 in 1976, 1986 and 1996 using the Elley-Irving and NZSEI scales.

\begin{tabular}{cccc}
\hline $\begin{array}{l}\text { Social } \\
\text { class } \\
\text { category }\end{array}$ & $\begin{array}{c}\text { 1976 Census } \\
\text { Elley-Irving }\end{array}$ & $\begin{array}{c}\text { 1986 Census } \\
\text { Elley-Irving }\end{array}$ & $\begin{array}{c}\text { 1996 Census } \\
\text { NZSEla }^{\mathbf{2}}\end{array}$ \\
\hline 1 & $5.7 \%$ & $6.4 \%$ & $4.9 \%$ \\
\hline 2 & $9.7 \%$ & $12.1 \%$ & $18.0 \%$ \\
\hline 3 & $23.6 \%$ & $23.3 \%$ & $21.2 \%$ \\
\hline 4 & $28.5 \%$ & $27.9 \%$ & $24.9 \%$ \\
\hline 5 & $23.2 \%$ & $21.0 \%$ & $21.3 \%$ \\
\hline 6 & $9.3 \%$ & $9.3 \%$ & $9.6 \%$ \\
\hline Total & $100 \%$ & $100 \%$ & $100 \%$ \\
\hline $\begin{array}{l}\text { Notes: } \\
\text { (a) Excludes farmers. }\end{array}$ & & & \\
\hline
\end{tabular}

predicted death rate for the 100th percentile of the social class scale was 1.8 times that of the 0 th percentile. In other words, the (weighted) average increase in mortality associated with a $100 \%$ change on the social class scale (from the 0th percentile to the 100th percentile) was 337 per 100,000 person-years, which represented a change in relative risk from 1.0 to 1.8 .

Table 2 also shows the corresponding analyses for 1985-87 (Elley-Irving) and 1995-97 (NZSEI), and Figure 1 shows the social class mortality trends in the three time periods. The strengths of the social class mortality trends, as measured by the Relative Index of Inequality, increased from 1.8 in $1975-77$ to 2.1 in 1985-87 to 2.3 in 1995-97. Direct comparison of the social class mortality patterns in the three time periods is complicated by the different social class scale used in the third time period. Nevertheless, the trend analyses, which take into account the differing

Table 2: Age-standardised mortality per 100,000 person-years and age-standardised rate ratios during 1975-77, 1985-87, and 1995-97 in New Zealand males aged 15-64 years, by Elley-Irving and NZSEl social class.

\begin{tabular}{|c|c|c|c|c|c|c|c|c|c|}
\hline \multirow[b]{2}{*}{ Category } & \multicolumn{3}{|c|}{ 1975-77 Elley-Irving } & \multicolumn{3}{|c|}{ 1985-87 Elley-Irving } & \multicolumn{3}{|c|}{ 1995-97 NZSEI } \\
\hline & Deaths & Rate & SRR & Deaths & Rate & SRR & Deaths & Rate & SRR \\
\hline \multicolumn{10}{|l|}{$\begin{array}{l}\text { Pooled rate } \\
\text { (all men aged }\end{array}$} \\
\hline Class 1 & 595 & 451 & 0.79 & 498 & 301 & 0.63 & 232 & 197 & 0.43 \\
\hline Class 2 & 1,228 & 459 & 0.81 & 1,323 & 409 & 0.85 & 1,272 & 380 & 0.83 \\
\hline Class 3 & 3,181 & 497 & 0.88 & 2,284 & 385 & 0.80 & 1,655 & 425 & 0.93 \\
\hline Class 4 & 3,142 & 537 & 0.95 & 2,942 & 504 & 1.05 & 2,023 & 499 & 1.09 \\
\hline Class 5 & 3,474 & 657 & 1.16 & 2,729 & 623 & 1.30 & 2,061 & 589 & 1.29 \\
\hline Class 6 & 1,803 & 864 & 1.52 & 1,237 & 614 & 1.28 & 980 & 559 & 1.22 \\
\hline $\begin{array}{l}\text { Pooled rate } \\
\text { (classes 1-6) }\end{array}$ & 13,423 & 568 & 1.00 & 11,013 & 479 & 1.00 & 8,124 & 457 & 1.00 \\
\hline $\begin{array}{l}\text { Ratio class } 6 \\
\text { to class } 1\end{array}$ & - & 1.9 & & - & 2.0 & & - & 2.8 & \\
\hline Intercept & - & 403 & & - & 309 & & - & 280 & \\
\hline Slope ${ }^{a}$ & & 3.37 & & & 3.51 & & & 3.71 & \\
\hline $\begin{array}{l}\text { Relative Index } \\
\text { of Inequality }\end{array}$ & & 1.8 & & & 2.1 & & & 2.3 & \\
\hline $\begin{array}{l}\text { Notes: } \\
\text { (a) The slope is th } \\
\text { (b) The Relative Ir } \\
\text { percentile (int }\end{array}$ & $\begin{array}{l}\text { change in } \\
\text { lex of Inequ } \\
\text { cept }+100\end{array}$ & $\begin{array}{l}\text { rate per } \\
\text { s the pre } \\
\text { ) agains }\end{array}$ & $\begin{array}{l}\text { entile ch } \\
\text { d relativ } \\
\text { th perc }\end{array}$ & $\begin{array}{l}\text { social clas } \\
\text { tem the line } \\
\text { tercept on }\end{array}$ & sion of & (n) & class per & core) fo & \\
\hline
\end{tabular}


sizes of the various social classes in the different time periods and classification systems and the overall decline in mortality, indicate that, if anything, the social class mortality gradient has increased between 1975-77 and 1995-97.

Table 3 shows the 1995-97 data by age group. It shows that, unlike previous analyses, ${ }^{1}$ the relative social class mortality gradient was just as strong in the older age-groups as in the younger age-groups, with the Relative Index of Inequality being 1.4 in the youngest age-group (15-24 years), and varying between 2.4 and 3.0 in the older age-groups. It should be noted, however, that the percentage of deaths that were unclassifiable was much greater in the 15-24 age group (55\%) than in other age groups (28\%).

\section{Discussion}

A number of potential methodological problems with analyses of this type have been discussed previously ${ }^{1}$ and in the wider literature, where the issues of the potentially artefactual nature of socio-economic inequalities in health, and of their persistence over time, has generated considerable debate. ${ }^{21}$ Of prime concern are potential biases caused by inaccurate reporting of occupation on Census forms and on death certificates, particularly when these two datasets are not directly linked, ${ }^{22}$ as in the current analyses. Such numerator-denominator biases have now been investigated in the New Zealand Census-Mortality Study, ${ }^{23}$ and it appears that they may affect the findings for some specific social class categories. In particular, numerator-denominator bias may be particularly strong for NZSEI social class 1 when using the standard cutoff point of 75 in the NZSEI score. However, such biases do not appear to be a major source of bias with regards to the overall social class mortality gradient. Our focus here is on comparing the social class mortality gradients across time, and there is no information available on whether such numerator-denominator
Figure 1: New Zealand male age-standardised mortality rate ratios by Elley-Irving social class 1975-77, 1985-87 and NZSEI social class 1995-97.

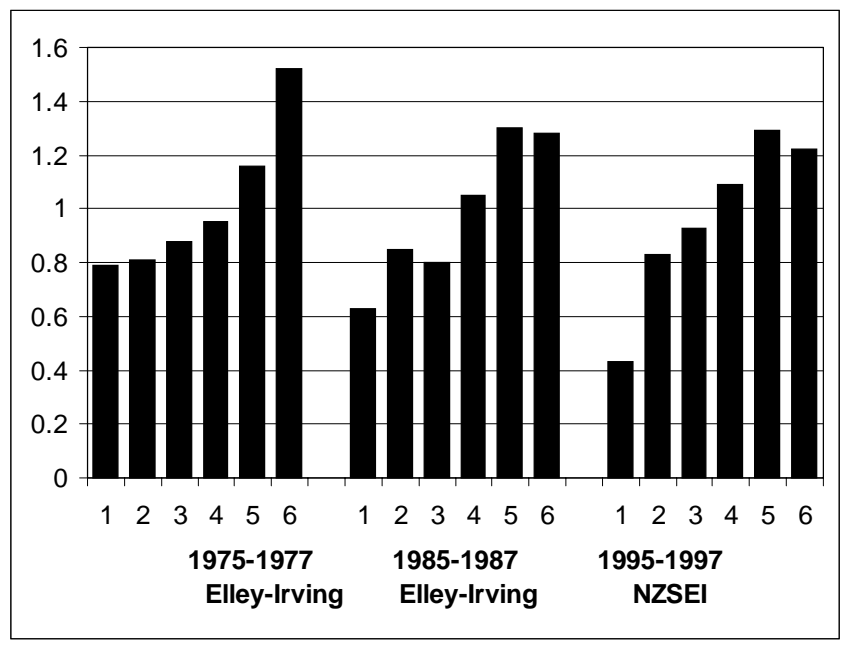

biases have strengthened or weakened over time, but it is probably unlikely that they could account for the time trends reported here.

A second methodological problem is that membership of the lower social classes could be a consequence, rather than a cause, of chronic disease, ${ }^{24}$ and that the persistence and possible widening of inequalities over time are the result of health selection and social mobility processes. ${ }^{25}$ In general, such occupational drift within the employed population appears most unlikely to account for the observed mortality differences. ${ }^{1}$ Of more concern in the current study is the related problem of drift between the employed and the unemployed population, particularly in a period of increasing unemployment. It has been argued that this bias would

Table 3: Age-specific mortality per 100,000 person-years and age-standardised rate ratios during $1995-97$ in New Zealand males aged 15-64 years, by NZSEI social class and age-group.

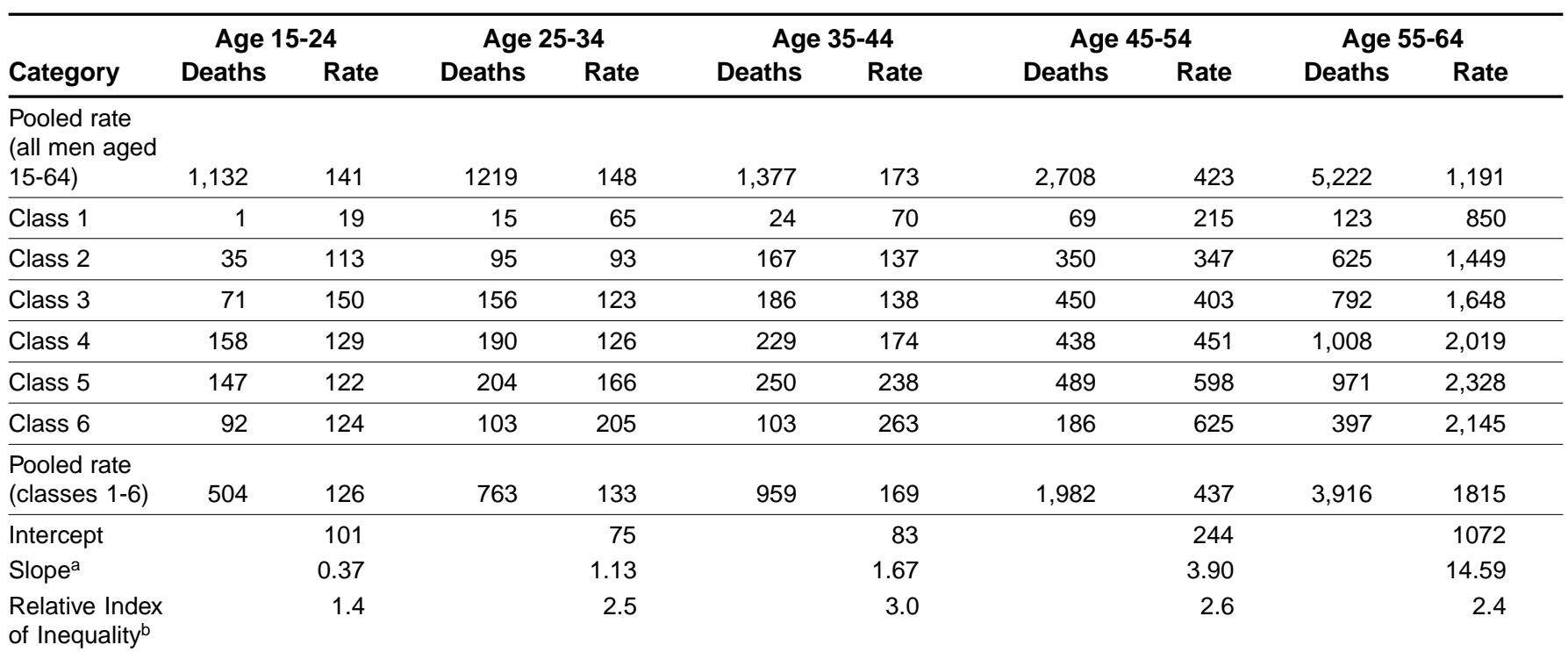

Notes:

(a) The slope is the change in death rate per percentile change in social class score.

(b) The Relative Index of Inequality is the predicted relative risk (from the linear regression of the deaths rates against social class percentile score) for the 100th percentile (intercept $+100 *$ slope) against the Oth percentile (intercept only). 
be likely to reduce rather than to increase the observed social class mortality differences, ${ }^{26}$ although the mortality data in our analyses involve 'current or most recent' occupation (rather than solely current occupation) and this bias is therefore likely to be small. ${ }^{27-29}$ Nevertheless, since the jobs lost in the 1980s and '90s were predominantly those requiring low skill levels, ${ }^{20}$ it is possible that such bias may in part account for the relatively low mortality rate in class 6 in the 55-64 age-group in the current study and in the 1985-87 analyses. ${ }^{7}$ In each instance, this lower rate in class 6 (than in class 5 ) in the oldest age group entirely accounts for the slightly lower age-standardised mortality rate in class 6 compared with class 5 . On the other hand, there is a suggestion that the lower apparent mortality rate for NZSEI class 6 compared with class 5 is a consequence of numerator-denominator bias. Analyses in the New Zealand Census-Mortality Study for the 1991-94 period using the decedent's occupation on the 1991 Census find that the mortality rate is greater in class 6 than class 5 (Blakely, personal communication).

A third major methodological problem with the current study is that the NZSCO classification changed markedly between 1985$87^{14}$ and 1995-97. ${ }^{15}$ This change will not bias the findings for 1995-97 in itself, but may make them non-comparable with the findings for the earlier time periods. In particular, it was not possible to use the previously used Elley-Irving classification for the 1995-97 analyses, and instead we used the recently developed New Zealand Socio-Economic Index (NZSEI). ${ }^{12}$ The NZSCO90 codes are less detailed than the NZSCO-68 codes, and it might therefore be expected that using the NZSCO-90 codes would result in more problems of random misclassification of social class. The resulting problems of misclassification would apply to both the numerator and denominator data for 1995-97 (both were based on the same three-digit NZSCO-90 codes) and would therefore be non-differential (with the exception of the exclusion of the data for farmers). Thus, these problems of misclassification would tend to reduce the magnitude of the observed social class mortality gradient. ${ }^{30}$ Despite this, we found a stronger social class mortality gradient for the most recent time period, a result that is consistent with the international literature demonstrating that different scales of occupational class generate quite similar health disparities. ${ }^{31}$ In fact, recent analyses by Blakely (personal communication) found very similar social class gradients when the Elley-Irving scale and the NZSEI scale (albeit using a different cutoff between classes 1 and 2) were both applied to the same dataset of mortality in males aged 45-64 years in 1991 for which the Census data were available for both the NZSCO-68 and NZSCO-90 codes. Thus, it seems unlikely that the increase in social class gradient over time reported here is due to the change in social class scale.

On balance, it seems reasonable to assume that the data presented here permit a valid comparison of the social class mortality patterns in the three time periods under study, although the findings must nevertheless be interpreted with caution. Although mortality declined by $15 \%$ between $1975-77$ and $1985-87$, and by a further $21 \%$ by $1995-97$, the relative social class differences in mortality have not decreased and may even have increased.

These findings are generally consistent with evidence that socioeconomic differences have increased in New Zealand in the past two decades. ${ }^{32-35}$ Between 1985 and 1990, New Zealand's GDP fell by $0.7 \%$, the worst record of any industrialised country, while unemployment more than doubled. ${ }^{35}$ From 1989 to 1991, official unemployment figures increased from $7.1 \%$ of the labour force to $10.6 \%,{ }^{32}$ and most household incomes fell in real terms by $7.3 \%$ with the greatest proportional falls occurring in poor families with children. ${ }^{32}$ The situation has improved in recent years, but this has occurred too recently to affect the analyses for 1995-97 reported here.

Explanations for the social class mortality differences have been sought at a number of levels, particularly since the publication of the Black report on inequalities in health in Britain ${ }^{21,36}$ and subsequent research showing that income inequality is a determinant of national mortality rates. ${ }^{37}$ Within a social science framework the contrast has been drawn between structural/materialist and behavioural/lifestyle explanations, ${ }^{21}$ in epidemiology between distal and proximate factors, ${ }^{38}$ and in health promotion theory between 'upstream' and 'downstream' interventions. ${ }^{39}$ Regardless of paradigm, investigators agree that socio-economic disadvantage affects all forms of disease and almost all key risk factors producing these diseases, as well as access to care. Furthermore, attempts to modify risk factors can on their own only have a limited effect on socio-economic disparities, although such interventions are likely to be more productive where attention is also paid to the broader social forces generating these disparities. ${ }^{40}$

The growth of research on income inequality has helped to throw light back on to the long-established individual-level association of personal socio-economic status with health. Lynch et $\mathrm{a}^{14}$ have summarised three possible explanations (from the social science perspective) for socio-economic differences in health: the individual income interpretation, the psychosocial environment interpretation, and the neo-material interpretation. The latter two interpretations are particularly relevant in the current context. The psychosocial environment interpretation proposes that socioeconomic differences affect health through perceptions of place in the social hierarchy, e.g. based on relative position according to income. ${ }^{42}$ Thus, indicators of 'social capital', such as trust and belonging to and volunteering for community organisations, are strongly related to mortality rates. In contrast, neo-materialist explanations ${ }^{43-45}$ argue that interpretations should start from the structural and material causes of inequalities rather than just perceptions of inequality.

Whatever the explanations of the differences, the primary significance of occupational and social class analyses is that they identify groups in the community that have an excess mortality which is potentially preventable. The findings of the current study indicate that this potential has not been fully realised in New Zealand. Social class differences have not decreased and may even have increased despite the overall decline in mortality. The findings of marked, persisting and even increasing socio-economic differentials in health are consistent with those for Europe, the 
United States and other developed countries. ${ }^{26,46,47}$ While these results might be taken to indicate that such differences are an intractable product of the economic system, there remain emphatic reasons for responding to health disparities of this kind ${ }^{48}$ since inequalities are unfair, they affect everyone, they are avoidable and, above all, interventions to reduce them are cost effective. Perhaps the first step to responding to a challenge of this nature is to ensure that the relevant information is available and close to the policy agenda. Thus, with reference to the previous New Zealand work, it has been argued that "the results give a startling view of the extent of inequalities in New Zealand society"49 and that the significance of the findings was not merely academic but had major policy implications. The challenge for public health and health service workers is to ensure that these striking mortality differences are not perpetuated into the new millennium.

\section{Acknowledgements}

This work was funded by a Limited Budget Grant and the Centre for Public Health Research receives funding support from the Research Council of New Zealand. We wish to thank Tony Blakely and Patrick Graham for their comments on the draft manuscript and for suggestions on the data analysis.

\section{References}

1. Pearce NE, Davis PB, Smith AH, Foster FH. Mortality and social class in New Zealand. I: Overall male mortality. $N$ Z Med J 1983;96:281-5.

2. Pearce NE, Davis PB, Smith AH, Foster FH. Mortality and social class in New Zealand. II: Male mortality by major disease groupings. $N$ Z Med J 1983;96:711-6.

3. Salmond C, Crampton P, Sutton F. NZDep91: A New Zealand index of deprivation. Aust N Z J Public Health 1998;22:835-7.

4. Pearce NE, Davis PB, Smith AH, Foster FH. Mortality and social class in New Zealand. III: Male mortality by ethnic group. $N$ Z Med J 1984;97:31-5.

5. Pearce NE, Davis PB, Smith AH, Foster FH. Social class. Ethnic group and male mortality in New Zealand 1974-78. J Epidemiol Community Health 1985;39:9-14

6. Pearce NE, Howard JK. Occupation, social class and male cancer mortality in New Zealand, 1974-78. Int J Epidemiol 1986;15:456-62.

7. Pearce NE, Marshall S, Borman B. Undiminished social class differences in New Zealand men. N Z Med J 1991;104:153-6.

8. Elley WB, Irving JC. A socioeconomic index for New Zealand based on levels of education and income from the 1966 Census. N Z J Educ Stud 1972; 7:153-67.

9. Elley WB, Irving JC. Revised socioeconomic index for New Zealand. $N Z J$ Educ Stud 1976;11:25-30.

10. Irving JC, Elley WB. A socio-economic index for the female labour force in New Zealand. J Educ Stud 1977;12:154-60.

11. Johnston R. A Revision of Socio-Economic Indices for New Zealand. Wellington: New Zealand Council for Educational Research, 1983.

12. Davis P, McLeod K, Ransom M, Ongley P, Pearce N, Howden-Chapman P. The New Zealand Socioeconomic Index: Developing and validating an occupationally-derived indicator of socio-economic status. Aust NZJ Public Health 1999;23:27-33.

13. Sporle A, Pearce N, Davis P. Social class mortality differences in Maori and non-Maori New Zealand men aged 15-64 during 1996-1997. $N$ Z Med J. In press 2001.

14. New Zealand Standard Classification of Occupations. Wellington: Department of Statistics, 1980.

15. New Zealand Standard Classification of Occupations. Wellington: Department of Statistics, 1992.

16. Rothman KJ, Greenland S. Modern Epidemiology 2nd ed. Philadelphia: Lippincott-Raven, 1998.

17. Segi M. Cancer Mortality for Selected Sites in 24 Countries (1950-1957).
Sendai(Japan): Department of Public Health, Tohoku University School of Medicine, 1960

18. Pearce NE, Cryer PC. Analyzing the components of a linear trend in proportions. Am J Epidemiol 1986;124:127-33.

19. Mackenbach JP, Kunst AE. Measuring the magnitude of socio-economic inequalities in health: An overview of available measures illustrated with two examples from Europe. Soc Sci Med 1997;44:757-71.

20. Howden-Chapman P, Tobias M. Social Inequalities in Health. Wellington: Ministry of Health, 2000.

21. Macintyre S. The Black report and beyond what are the issues? Soc Sci Med 1997;44:723-45.

22. Alderson MR. Some sources of error in British occupational mortality data. Br J Ind Med 1972;29:245-54.

23. Blakely T, Woodward A, Pearce N, Salmond C, Kiro C, Davis P. Socioeconomic factors and mortality among 25-64 year olds followed from 1991 to 1994: The New Zealand Census Mortality Study. NZ Med J. In press 2001.

24. Fox AJ, Goldblatt PO, Adelstein AM. Selection and mortality differentials. J Epidemiol Community Health 1982;36:69-79.

25. Illsley R. Occupational class, selection and the production of inequalities in health. $Q J$ Soc Aff 1986;2:151-65.

26. Marmot MG, McDowall ME. Mortality decline and widening social inequalities. Lancet 1986;ii:274-6.

27. Kunst A, Groenhof F, Mackenbach J. The EU working group on socioeconomic inequalities in health. Mortality by occupational class among men 3064 years in 11 European countries. Soc Sci Med 1998;46:1459-76.

28. Kunst A, Groenhof F, Borgan J-K, Costa G, et al. Socio-economic inequalities in mortality. Methodological problems illustrated with three examples from Europe. Rev Epidemiol Sante Publique 1998;46:467-79.

29. Martikainen P, Valkonen T. Bias related to the exclusion of the economically inactive in studies on social class differences in mortality. Int J Epidemiol 1999;28:899-904.

30. Copeland KT, Checkoway H, McMichael AJ, et al. Bias due to misclassification in the estimation of relative risk. Am J Epidemiol 1977;105: 488-95.

31. Bartley M, Carpenter L, Dunnell K, Fitzpatrick R. Measuring inequalities in health: an analysis of mortality patterns using two social classifications. Sociol Health Illness 1996;18:455-74.

32. Pearce N. Economic policy and health in The Year of the Family. $N Z$ Med J 1994;107:379-81.

33. Kelsey J. The New Zealand Experiment: A World Model for Structural Adjustment? Auckland: Auckland University Press, 1995.

34. Easton B. The Commercialization of New Zealand. Auckland: Auckland University Press, 1997.

35. Hewlett, SA. Child Neglect in Rich Nations. New York: United Nations International Children's Economic Fund, 1993.

36. Working Group on Inequalities in Health. Inequalities in Health [report] London: Department of Health and Social Security, 1980.

37. Wilkinson RG. Income distribution and life expectancy. $\mathrm{Br}$ Med $J$ 1992;304:165-8.

38. Link BG, Phelan J. Social conditions as fundamental causes of disease. J Health Soc Behav 1995; Spec Issue: 80-94.

39. Pearce N, McKinlay J. Back to the future in epidemiology and public health. J Clin Epidemiol 1998;51:643-6.

40. House JS, Williams DR. Understanding and reducing socioeconomic and racial/ethnic disparities in health. In: Smedley BD, Syme SL, editors. Promoting Health, Intervention Strategies from Social and Behavioral Research. Washington(DC): National Academy Press, 2000;81-124.

41. Lynch JW, Davey Smith G, Kaplan GA, House JS. Income inequality and mortality: importance to health of individual income, psychosocial environment, or material conditions. Br Med J 2000;320:1200-4

42. Wilkinson RG. Unhealthy Societies: The Afflictions of Inequality. London Routledge, 1996.

43. Davey Smith G. Commentary: understanding it all - health meta-theories and mortality trends. Br Med J 1996;313:1584-5.

44. Blane D, Bartley M, Davey Smith G. Disease aetiology and materialistic explanations of socio-economic mortality differentials. Eur J Public Health 1997; 7:385-91.

45. Davey Smith G, Blane D, Bartley M. Explanations for socio-economic differentials in mortality: Evidence from Britain and elsewhere. Eur J Public Health 1994;4:131-44

46. Kunst A, Groenhof F, Mackenbach J. The EU working group on socioeconomic inequalities in health. Mortality by occupational class among men 3064 years in 11 European countries. Soc Sci Med 1998;46:1459-76.

47. Pappas G, Queen S, Hadden W, Fisher G. The increasing disparity in mortality between socioeconomic groups in the United States, 1960 and 1986. N Engl J Med 1993;329:103-9.

48. Woodward A, Kawachi I. Why reduce health inequalities? J Epidemiol Community Health 2000;54:923-9.

49. Paul C. Social class and health. N Z Med J 1985;98:100-1. 